PRAMANA

(C) Indian Academy of Sciences

Vol. 86, No. 6

— journal of

June 2016

physics

pp. 1413-1413

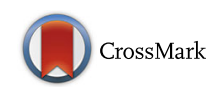

\title{
Erratum to: Robust adaptive synchronization of general dynamical networks with multiple delays and uncertainties
}

\author{
YIMING LU ${ }^{1,3}$, PING HE ${ }^{2}$, , SHU-HUA MA ${ }^{3}$, GUO-ZHI LI ${ }^{4}$ and \\ SALEH MOBAYBEN ${ }^{1}$ \\ ${ }^{1}$ Laboratory of Train Network, Department of Train Control Tech., Research Center of Product \\ \& Tech., CRRC TANGSHAN CO., LTD, No. 3, Changqian Rd, Fengrun DIST, Tangshan, \\ Hebei, 063035, People's Republic of China \\ ${ }^{2}$ School of Automation and Electronic Information, Sichuan University of Science and \\ Engineering, Zigong, Sichuan, 643000, People's Republic of China \\ ${ }^{3}$ School of Information Science and Engineering, Northeastern University, Shenyang, \\ Liaoning, 110819, People's Republic of China \\ ${ }^{4}$ State Key Laboratory of Robotics and System, Harbin Institute of Technology, Harbin, \\ Heilongjiang, 150080, People's Republic of China \\ *Corresponding author. E-mail: pinghe@ suse.edu.cn; pinghecn@qq.com
}

MS

DOI: 10.1007/s12043-016-1203-0; ePublication: 22 April 2016

The affiliations of the authors were inaccurate in the original publication (DOI: 10.1007/s12043-015-1182-6). The correct affiliation of all five authors are provided here. 